\title{
ACTIVATED CARBON FROM THERMO-COMPRESSED WOOD AND OTHER LIGNOCELLULOSIC PRECURSORS
}

\author{
Lotfi Khezami, Aissa Ould-Dris and Richard Capart*
}

\begin{abstract}
The effects of thermo-compression on the physical properties such as bulk density, mass yield, surface area, and also adsorption capacity of activated carbon were studied. The activated carbon samples were prepared from thermo-compressed and virgin fir-wood by two methods, a physical activation with $\mathrm{CO}_{2}$ and a chemical activation with $\mathrm{KOH}$. A preliminary thermo-compression method seems an easy way to confer to a tender wood a bulk density almost three times larger than its initial density. Thermo-compression increased yield regardless of the mode of activation. The physical activation caused structural alteration, which enhanced the enlargement of micropores and even their degradation, leading to the formation of mesopores. Chemical activation conferred to activated carbon a heterogeneous and exclusively microporous nature. Moreover, when coupled to chemical activation, thermo-compression resulted in a satisfactory yield $(23 \%)$, a high surface area $\left(>1700 \mathrm{~m}^{2} \cdot \mathrm{g}^{-1}\right)$, and a good adsorption capacity for two model pollutants in aqueous solution: methylene blue and phenol. Activated carbon prepared from thermo-compressed wood exhibited a higher adsorption capacity for both the pollutants than did a commercial activated carbon.
\end{abstract}

Keywords: Wood, Activated carbon, Thermo-compression, Microporosity, Adsorption properties

Contact information: Université de Technologie de Compiègne, Département de Génie Chimique. Laboratoire de Génie des Procédés Industriels, UMR 6067 du CNRS-BP 20529 - 60205 Compiègne, France.

*Corresponding author: richard.capart@utc.fr, Tel: 3334423 44 45; Fax: 33344231980

\section{INTRODUCTION}

Activated carbon is used in a host of applications due to its adsorption capacity in gaseous or liquid phase. These applications can be found in many fields such as food industry, environment, water treatment, and catalysts manufacturing. Producing activated carbon consists of heating the precursor up to a temperature approximately between 600 and $1000{ }^{\circ} \mathrm{C}$ (Guo and Lua 1998). Two successive phases occur during heating:

- a first phase of pyrolysis associated with a strong devolatilisation of the precursor, leading to a carbon-enriched product.

- a subsequent phase of activation in which micro and mesopores develop within the carbonaceous matrix.

Many authors (Marsh 1987; Pastor-Villegas et al. 1998) reported works where the pyrolysis of the lignocellulosic precursor, without any subsequent activation, resulted in the formation of activated carbon (A.C.). The microporous structure is developed due to the removal of the volatile matter and to the progressive shrinkage that is, according to PastorVillegas et al. (1998), responsible for pore narrowing.

Activated carbon obtained from pyrolysis is considerably improved by activation treatment. There are two distinct ways of activation, which are commonly termed as physical and chemical activation. In physical activation, the activating agents are oxidising gases: $\mathrm{CO}_{2}$ (Rodriguez-Reinoso and Molina-Sabio 1994) or $\mathrm{H}_{2} \mathrm{O}$ (Warhurst et al. 1997), which react with carbon. According to Walker (1996), activation with $\mathrm{CO}_{2}$ makes it possible to achieve a 
greater uniformity of pores compared with activation using $\mathrm{H}_{2} \mathrm{O}$. The reaction mechanism is actually complex, involving the fixation and then the dissociation of $\mathrm{CO}_{2}$ on active sites to form unstable intermediates, and the reaction is catalysed by inorganic compounds constituted by ashes.

In chemical activation, the development of the porous structure is important, and the required temperatures are generally lower than those prevailing in physical activation with $\mathrm{CO}_{2}$ or $\mathrm{H}_{2} \mathrm{O}$. The activating agents are mainly inorganic compounds, introduced before heating by impregnation within the precursor (raw biomass or char). These activating agents can be acids $\mathrm{H}_{3} \mathrm{PO}_{4}$ (Toles et al. 1996), $\mathrm{H}_{2} \mathrm{SO}_{4}$ (Guo and Lua 1999), alkaline products $\mathrm{KOH}$ (Ubago-Pérez et al. 2006, Hu and Srinivasan 1999; Ahmadpour and Do 1996), or salts $\mathrm{ZnCl}_{2}$ (Ahmadpour and Do 1996; Lopez-Gonzalez et al. 1980). Generally, chemical activation does not require as high temperatures as physical activation. In the industrial practice, activated carbon is often produced from a combination of these two modes of activation. Chemical activation using $\mathrm{KOH}$ was developed more recently than the other modes of activation. Thus, the $\mathrm{KOH}$ activated carbon has been commercially available only since the 1980s (O'Grady and Wennerberg 1986). Since then, extensive research has been devoted to this process. It was thus demonstrated that activation with $\mathrm{KOH}$ yields activated carbon with a highly microporous structure and a narrow pore-size distribution, while activation with an acidic agent $\left(\mathrm{H}_{3} \mathrm{PO}_{4}\right)$ leads to a broader pore-size distribution and a larger production of macropores (Issa and Teresa 2000).

A link could be established between the development of pores and the catalytic activity of inorganic compounds containing some alkaline metal. In these alkaline catalysts, the atoms of oxygen also play a major role in the process of carbon oxidation, leading to the formation of pores. The actual mechanism of activation has not yet been definitely established. In the literature, various descriptions were proposed for this mechanism. For instance, Franck and Meraikib (1970) have postulated that the alkali metal intercalates in the lattices of carbon and acts as an electron donor, which promotes the reaction during gasification. In studying the effect of $\mathrm{KOH}$ on various cokes, Marsh et al. (1984) stated that the presence of oxygen in alkali resulted in the removal of cross-linking of carbon atoms in crystallites. The potassium metal liberated at high temperature may intercalate and force apart the separate lamellae of the crystallite. Hüttinger and Minges (1986) and Ehrburger et al. (1986) have given slightly different explanations of the mechanism.

In order to reduce the production costs, several manufacturers use precursors' wastes and by-products from agriculture and forestry (Gergova et al. 1994). Among the various other precursors, there are wood-sawdust (Tsai et al. 2001), stones of olives (Lopez-Gonzalez et al. 1980) and various fruits, sugar cane bagasse, trunks of palm trees, walnut shells, etc. For instance, coconut shell (Hu and Srinivasan 1999; Laine and Yunes 1992; Laine et al. 1989; Sodya et al. 1997) is a widely accepted material owing to its abundance and the quality of the derived activated carbon. Moreover, the good mechanical properties of the granules of carbon obtained from coconut shells partly results from the high density of this precursor.

In the present work, an attempt was made to confer to lumps of fir-wood, a density similar to that of a material like coconut shell, by thermo-compression. Two modes of activation were applied: a physical activation with $\mathrm{CO}_{2}$ and a chemical activation with $\mathrm{KOH}$. Classical investigations methods such as the pore surface area by BET method were performed on activated carbons. Activated carbon from thermo-compressed wood has been previously tested for the removal of chromium VI in aqueous solutions (Khezami and Capart 2005). In the present study, the adsorption capacity of A.C. from thermo-compressed wood was evaluated for two organic pollutants in aqueous phase: methylene blue and phenol. These two molecules are very often used to characterize the adsorption capacity of activated carbon. 
Methylene blue is a typical product of the dye industry and can be regarded as a model compound for the removal of high molecular weight organic contaminants. The produced activated carbon from different raw materials according to different modes of activation have been compared with a commercial activated carbon (acticarbone CXV) supplied by CECA (France).

\section{EXPERIMENTAL}

\section{Raw Material and Thermo-Compression}

The raw material consisted of lumps of fir wood, the dimension of which being $12 \times 16 \times 20 \mathrm{~mm}(20 \mathrm{~mm}$ in the direction of fibres). The initial density of wood lump lay in the range $0.47-0.55{\mathrm{~g} . \mathrm{cm}^{-3}}^{-}$A part of them were compressed by using a hydraulic press Carver, equipped with 2 heating plates $(15 \times 15 \mathrm{~cm}$ by side). The maximal load of the press was 12 metric tons. Compression of fir-wood lumps was always made in the direction perpendicular to that of fibres. From previous trials of thermo-compression, it was shown that the ideal temperature of plates lies between 180 and $220{ }^{\circ} \mathrm{C}$. Above approximately $220{ }^{\circ} \mathrm{C}$, thermal decomposition of wood starts and the lumps tend to burst. The pre-moistening of wood by steam or hot water favours the thermo-compression but is not essential.

\section{Preparation of activated carbon}

The carbonisation-activation of fir-wood and other precursors was made in a stainless steel cylindrical reactor, $6 \mathrm{~cm}$ in diameter, vertically set up. The reactor was connected to cylinders of compressed gas $\left(\mathrm{N}_{2}\right.$ and $\left.\mathrm{CO}_{2}\right)$ and the flow-rate of gas was controlled by a flowmeter. The activated carbon was produced from 3 kinds of treatment:

(i) A simple pyrolysis i.e. a heating under $\mathrm{N}_{2}$ atmosphere

(ii) A "physical activation" or a heating under $\mathrm{CO}_{2}$ atmosphere

(iii) A "chemical activation" i.e. a heating of the precursor material impregnated with $\mathrm{KOH}$

For the simple treatment of pyrolysis, the operating variables were the heating rate $(3$ and 5 ${ }^{\circ} \mathrm{C} / \mathrm{min}$ ), the temperature of plateau, and the duration at temperature of plateau.

For the physical activation under $\mathrm{CO}_{2}$, the operating parameters specifically studied were the maximal temperature of activation (or the temperature of plateau), between $700{ }^{\circ} \mathrm{C}$ and $900{ }^{\circ} \mathrm{C}$, and the time of plateau, between 3 and 9 hours.

The used method for chemical activation was typically that proposed by $\mathrm{Hu}$ and Srinivasan (1999). In this method two successive steps are required: at first, the precursor was slowly carbonised under $\mathrm{N}_{2}$ at $300{ }^{\circ} \mathrm{C}$ for one hour. The charcoal so produced was then impregnated, after cooling, with a boiling concentrated solution of $\mathrm{KOH}$, in order to get $\mathrm{KOH}$ contents varying from 0.125 to 1 . The $\mathrm{KOH}$ content being defined as the mass ratio: $\mathrm{KOH} /$ anhydrous precursor.

At the end of each chemical activation treatment, the activated carbon was abundantly washed, firstly with a solution of $\mathrm{HCl} 0.1 \mathrm{M}$, then with distilled water up to a neutral $\mathrm{pH}$. The produced A.C. is designated as following in the tables and figures: M.A./R.M./T/tp.

For example: $\mathrm{CK}_{0.5} / \mathrm{Wc} / 800 / 2$ designates a $\mathrm{KOH}$ activated carbon prepared from thermo-compressed wood at $800^{\circ} \mathrm{C}$ for a time of plateau of 2 hours with $\mathrm{KOH} /$ char ratio equal to 0.5 . By default the mass ratio is equal to 1 . 
M.A. is the mode of activation with

NP: carbonisation under $\mathrm{N}_{2}$

CP: physically activated carbons under $\mathrm{CO}_{2}$

$\mathrm{CK}$ : chemically activated carbons with $\mathrm{KOH}$.

R.M. is the raw material with

$\mathrm{W}$ : virgin wood

Wc: thermo-compressed wood

$\mathrm{CN}$ : coconut shell

OS: olive stone.

$\mathrm{T}$ is the Temperature of plateau: $600,750,800,850{ }^{\circ} \mathrm{C}$.

tp is the time in plateau : $1,2,3,6,9$ hours.

\section{Caracterization of Samples}

After each experiment, a part of the produced A.C. was milled into powder in order to characterise its porosity and the adsorption parameters for both of the model pollutants. The characteristics of pores were evaluated from the adsorption-desorption isotherms of $\mathrm{N}_{2}$ at 77 $\mathrm{K}$, through an apparatus ASAP 2010 (Micromeritics). Before each determination of isotherm, the A.C. sample was outgased for 12 hours at $300{ }^{\circ} \mathrm{C}$ under vacuum. The surface area of pores was calculated from the BET equation (Brunauer, Emmett and Teller). The volume of micropores and the surface area attributed to mesopores were calculated from the t-plot method of Lippens and de Boer (Lippens and de Boer 1965). For both of the model pollutants, phenol and methylene blue, the parameters of the models of Langmuir and Freundlich were evaluated after determination of experimental data of sorption at $25^{\circ} \mathrm{C}$, thus detailed. Several Erlenmeyer flasks were filled up with a suspension of A.C. $(30 \pm 0.1 \mathrm{mg})$ in $100 \mathrm{ml}$ of a diluted solution of pollutant at various concentrations. The initial concentration of phenol was stepped from 10 to $150 \mathrm{mg} \mathrm{l}^{-1}$, while that of methylene blue from 30 to $200 \mathrm{mg} \mathrm{l}^{-1}$. After 24 hours of stirring, liquid samples from each flask were taken out and filtered. Their concentrations in non adsorbed free pollutant were measured by absorption spectrometry, UV at $269 \mathrm{~nm}$ of wavelength in the case of phenol, visible at $660 \mathrm{~nm}$ in the case of methylene blue. According to the theory of adsorption, the model of Langmuir is based on the fixation of a monolayer of adsorbate molecules on the surface of pores. Its mathematical formulation is the following (Langmuir 1918):

$$
q_{e}=\frac{Q_{0} \cdot b \cdot C_{e}}{1+b \cdot C_{e}}
$$

where $q_{e}\left(\mathrm{mg}^{-1} \mathrm{~g}^{-1}\right)$ is the amount of solute adsorbed by $1 g$ of activated carbon at the equilibrium concentration $C_{e}\left(\mathrm{mg} \cdot \mathrm{l}^{-1}\right) \cdot Q_{0}\left(\mathrm{mg} \cdot \mathrm{g}^{-1}\right)$ and $b\left(\mathrm{l} \cdot \mathrm{mg}^{-1}\right)$ are the Langmuir constants characterising the ultimate adsorption capacity and the surface binding energy respectively.

The amount of adsorbed solute $q_{e}$ was determined as follows:

$$
q_{e}=\frac{\left(C_{0}-C_{e}\right) \cdot V}{m_{a c}}
$$

In the equation (2) $C_{0}$ is the initial concentration (mg. $\left.1^{-1}\right), V$ the volume of the pollutant solution (1) and $m_{a c}$ the mass of activated carbon in the volume $V$.

The constants $Q_{0}$ and $b$ were determined from the linear form of Langmuir equation i.e.:

$$
\frac{C_{e}}{q_{e}}=\frac{1}{Q_{0}} C_{e}+\frac{1}{b \cdot Q_{0}}
$$


If the adsorption isotherms are of type $\mathrm{L}$, as it is the case for both the pollutants in the present work (fig. 4, 5, 7, and 8), then the empirical equation of Freundlich (Benefield et al. $1982)$ is well suited. It is defined by the following relationship in which $k\left[\mathrm{mg} \cdot \mathrm{g}^{-1}\left(1 . \mathrm{mg}^{-1}\right)^{1 / n}\right]$ and $n$ are empirical constants.

$$
q_{e}=k C_{e^{\frac{1}{n}}}
$$

The values of $k$ and $1 / n$ are respectively obtained from the intercept and the slope of the linear plot of $\ln \left(q_{e}\right)$ versus $\ln \left(C_{e}\right)$. The constant k can be defined as the sorption or the distribution coefficient, and represents the quantity of adsorbed pollutant for a unit equilibrium concentration (i.e., $C_{e}=1$ ). The slope $1 / n$ is a measure of the sorption intensity. For $n=1$, the partition between the two phases is independent of the concentration. A value of $1 / n$ below one indicates a normal Langmuir isotherm (of type L) while $1 / n$ above one is indicative of a cooperative sorption i.e. with strong interactions between the molecules of adsorbate themselves.

For predicting the favourability of an adsorption system, the Langmuir equation, like the Freundlich equation, can also be expressed in terms of a dimensionless separation factor $R_{L}$, defined as (Mckay et al.1982):

$$
R_{L}=\frac{1}{1+b \cdot C_{0 \max }}
$$

$C_{0 \max }$ being the initial concentration of the pollutant in solution. The $R_{L}$ value implies the adsorption to be either unfavourable $\left(R_{L}>1\right)$, linear $\left(R_{L}=1\right)$, favourable $\left(0<R_{L}<1\right)$ or irreversible $\left(R_{L}=0\right)$.

\section{RESULTS AND DISCUSSION}

\section{Thermo-compression of Fir Wood}

Thermo-compression at $180{ }^{\circ} \mathrm{C}$ resulted in a slight weight loss of wood, about $0.8 \%$ on a dry basis and about 7 to $8 \%$ on a wet basis. The weight loss corresponds to the moisture content of wood, in equilibrium with the ambient air.

The rheological properties of wood suddenly changed when temperature reached 180 ${ }^{\circ} \mathrm{C}$. Some softening and plasticisation of wood occurs at these temperatures. Thermocompression involves a strong flattening of the fir lumps. Typically, the thickness of lumps was reduced from 12 to about $2 \mathrm{~mm}$, whereas their breadth increased from 17 to $41 \mathrm{~mm}$. Their length (i.e. in the fibres direction) did not change significantly. Figure 1 illustrates the simultaneous changes of thickness and breadth as a function of the load (in tons) applied by the press on a single lump of fir. It can be noted that the breadth linearly varied with load, while this was not the case for thickness. As a consequence of thermo-compression, the density of a wood lump increased by its flattening (Fig. 2).

The compression, up to a load of 5 tons, made it possible to multiply by 2.6 the initial density of a single lump of fir-wood, providing a slab with a density similar to that of coconut shell and larger than the average density of oak wood. A maximal load of 5 tons corresponds to a final pressure of $600 \mathrm{kgf} / \mathrm{cm}^{2}$ applied on the wood lump. The pressure required to reach this density ratio was significantly lower than those experienced by Abe et al. (2001), between 1000 and $3000 \mathrm{kgf} / \mathrm{cm}^{2}$, at ambient temperature. These authors found densities of compressed wood only twofold that of virgin wood. 


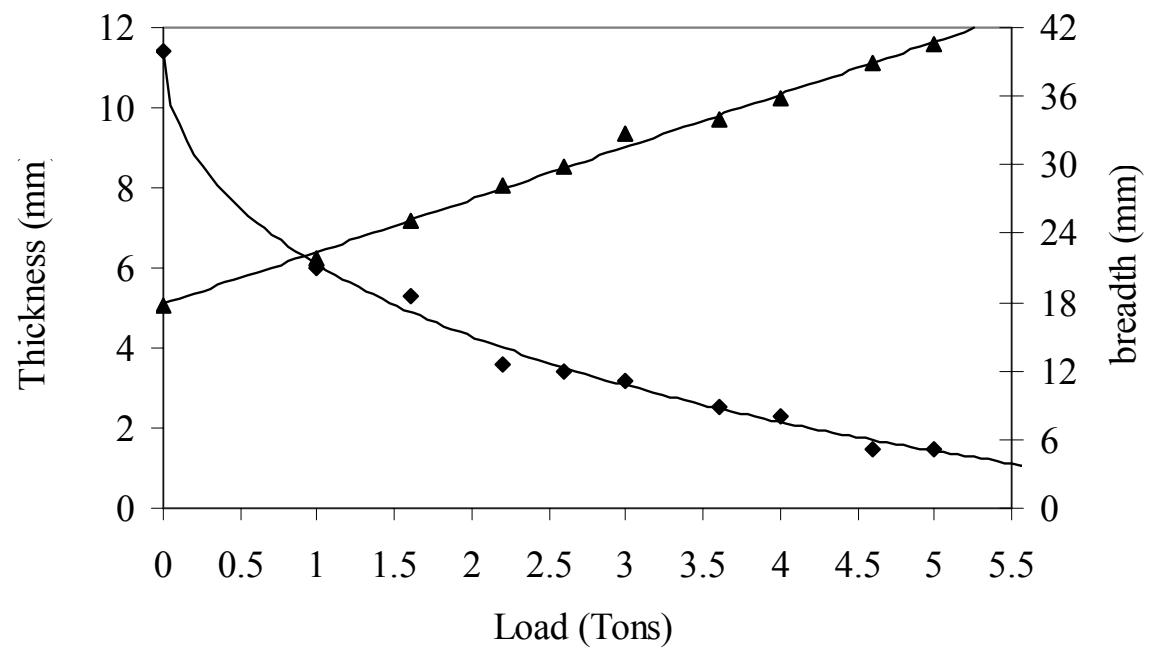

Fig. 1: Effect of thermo-compression at $180^{\circ} \mathrm{C}$ on the dimensions of a fir lump. $(\mathbf{\Lambda})$ breadth, ( $\bullet$ thickness

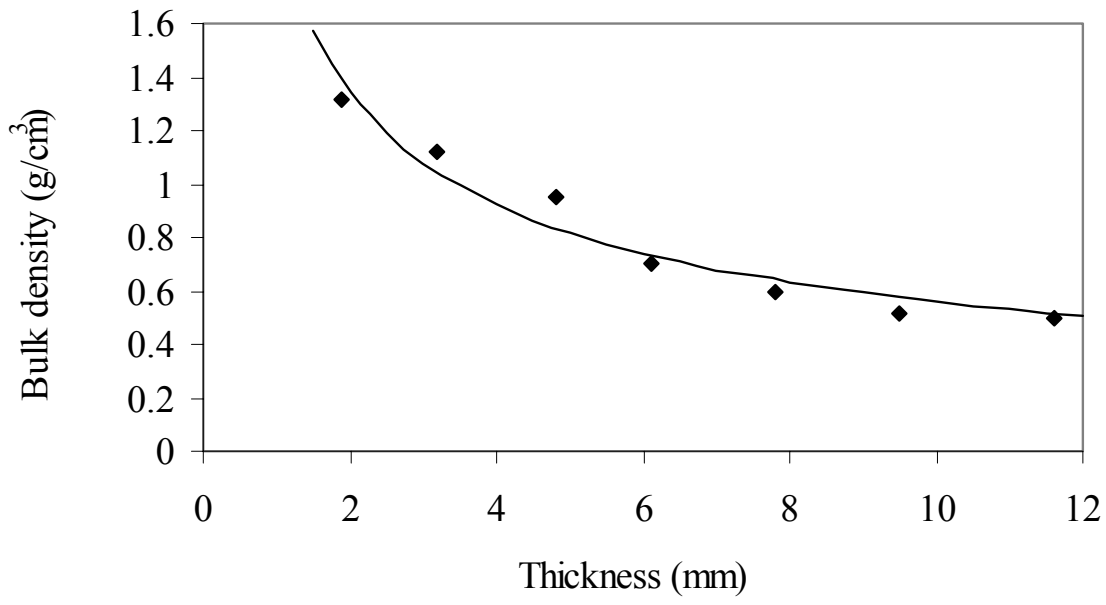

Fig. 2: Effect of thermo-compression at $180^{\circ} \mathrm{C}$ on the bulk density of a fir lump.

\section{Pyrolysis}

In the case of a simple pyrolysis, without activation, the yield in charcoal increased with the extent of compression. This yield rose from $23.35 \%$ to $24.52 \%$ at a plateau temperature of $600{ }^{\circ} \mathrm{C}$. Abe et al. (2001) also found a slight increase of pyrolysis yield of about $1.5 \%$ by compression. During pyrolysis, the volatile tar products do not readily escape from a solid matrix, since they are densified by thermo-compression. As a possible consequence of the increased retention of volatile tars, the so called secondary reactions of pyrolysis are promoted, yielding thereby more solid carbon generated after graphitisation reactions. The yields found in this work are comparable to those found by Byrne and Nagle (1997a) that have pyrolysed seven wood species and found yields ranging from 24.8 to 32.5 percent.

A simple pyrolysis does not result in good properties for the produced char. The BET surface area of pyrolysed chars never exceeded $300 \mathrm{~m}^{2} \mathrm{~g}^{-1}$. It even decreased with temperature and dropped to $27 \mathrm{~m}^{2} \mathrm{~g}^{-1}$ at $800{ }^{\circ} \mathrm{C}$. These results are similar to those obtained by $\mathrm{Hu}$ and Srinivasan (1999), who reported a BET surface area as low as $16 \mathrm{~m}^{2} \mathrm{~g}^{-1}$ for the pyrolysis of 
coconut shells. A decrease in the mass yield was observable when increasing the maximal temperature of pyrolysis from $600{ }^{\circ} \mathrm{C}$ to $800{ }^{\circ} \mathrm{C}$. With only pyrolysed chars, the adsorption capacity of methylene blue appeared very low in comparison to that of phenol, which is relatively more significant. The influence of main components of wood, cellulose, hemicelluloses and lignin on the development of pores during pyrolysis was discussed by Khezami et al. (2005). It was found that cellulose plays a major role. Cellulose chains, partially crystalline, are associated in microfibrils. As stated by Byrne and Nagel (1997b), cellulose microfibrils dominate the mechanism of dimensional change during pyrolysis. This shrinkage is attributed to the formation of graphitic layers resulting from the aromatisation process after thermal decomposition of glycosidic chains. Authors including Pastor-Vilegas et al. (1998) and Babel (2003) have emphasised that micropores are essentially constituted by spaces created between the graphitic layers.

\section{Physical Activation}

The activation results from the oxidation of carbon according to the heterogeneous gas-solid reaction: $\mathrm{C}+\mathrm{CO}_{2} \rightarrow 2 \mathrm{CO}$. This reaction tends to create pores within the matrix of carbon, leading to a mass loss of A.C. The characterisation of the porous structure usually has been made by physical adsorption of an inert gas, such as nitrogen or argon under reduced pressure. The shape of isotherms provides information about the sizes of pores, which are usually divided into micro, meso, and macropores. Figure 3 illustrates the shape of the $\mathrm{N}_{2}$ adsorption-desorption isotherm at $77 \mathrm{~K}$ for the $\mathrm{CO}_{2}$-activated carbon. The isotherms shown in Fig. 3 are clearly of type II, with a hysteresis of H4 type (Rouquerol et al. 1999). Occurring at elevated relative pressure $P / P_{0}$, the hysteresis of $\mathrm{H} 4$ type is due to the filling up of mesopores by capillary condensation. When the physical activation is increased, the walls of some micropores can be destroyed, yielding mesopores. This phenomenon of pore coalescence was reported by Rodriguez-Reinoso and Molina-Sabio (1994) for the activation of various cellulosic wastes (olive stones and almond shells). They found that in all cases, activation with $\mathrm{CO}_{2}$ opens and widens micropores into meso and macropores. According to these investigators, the ablation of the outside of the particle is significant at high burn-off, indicating a complete destruction of the wall of pores. The various characteristics of physically activated carbons, particularly the parameters $Q_{0}$ and $b$ for both the model pollutants, are presented in Table 1.

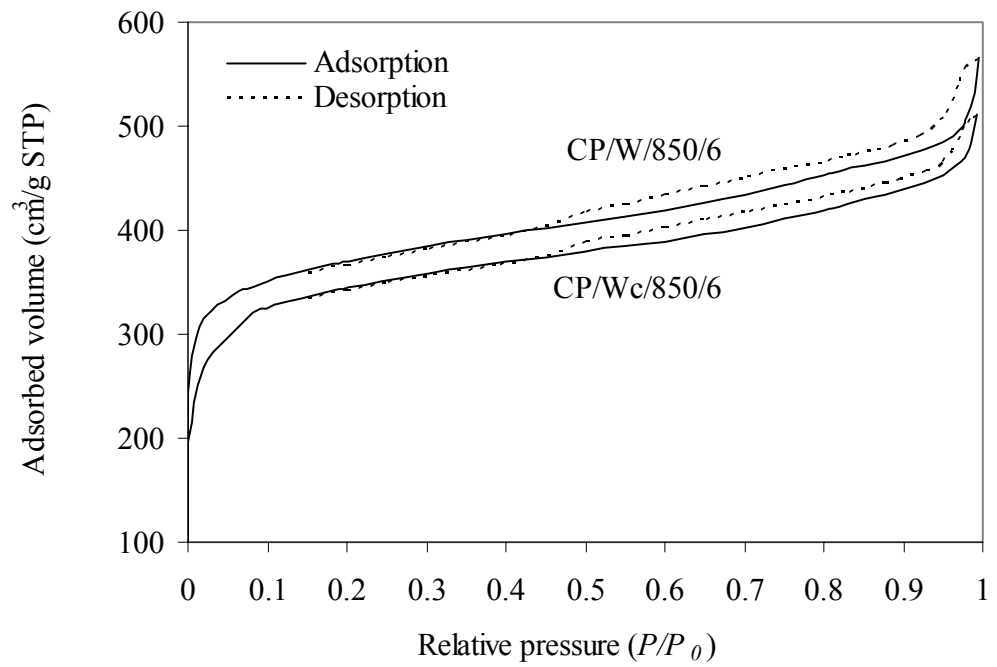

Fig. 3: $\mathrm{CO}_{2}$ activated carbon. Adsorption-desorption isotherms of $\mathrm{N}_{2}$ at $77 \mathrm{~K}$ 
Table 1: Main characteristics of $\mathrm{CO}_{2}$ activated carbons and pyrolytic char

\begin{tabular}{|c|c|c|c|c|c|c|c|c|c|c|c|c|}
\hline \multirow{2}{*}{$\begin{array}{l}\text { Active } \\
\text { Carbon }\end{array}$} & \multirow{2}{*}{$\begin{array}{l}\text { Mass } \\
\text { yield }\end{array}$} & \multirow{2}{*}{$\begin{array}{l}\text { S.BE } \\
T\end{array}$} & \multicolumn{5}{|c|}{ Methylene Blue } & \multicolumn{5}{|c|}{ Phenol } \\
\hline & & & $Q_{0}$ & $b$ & $R_{L}$ & $1 / n$ & $k$ & $Q_{0}$ & $b$ & $R_{L}$ & $1 / n$ & $k$ \\
\hline CP/W/750/3 & 15.90 & 587 & 190.89 & 0.02 & 0.2000 & 0.227 & 107.65 & 103.95 & 0.35 & 0.0187 & 0.336 & 24.73 \\
\hline $\mathrm{CP} / \mathrm{W} / 750 / 6$ & 11.66 & 938 & 238.09 & 2.93 & 0.0017 & 0.122 & 172.55 & 123.45 & 0.75 & 0.0088 & 0.243 & 32.37 \\
\hline CP/W/750/9 & 9.64 & 963 & 454.54 & 5.50 & 0.0009 & 0.099 & 317.77 & 217.4 & 0.92 & 0.0072 & 0.158 & 100.26 \\
\hline $\mathrm{CP} / \mathrm{W} / 850 / 3$ & 11.82 & 734 & 312.04 & 3.44 & 0.0014 & 0.130 & 213.07 & 136.89 & 0.68 & 0.0097 & 0.322 & 33.21 \\
\hline CP/W/850/6 & 5.60 & 1257 & 666.67 & 7.48 & 0.0007 & 0.102 & 472.67 & 188.68 & 0.29 & 0.0224 & 0.283 & 54.02 \\
\hline $\mathrm{NP} / \mathrm{Wc} / 600 / 1$ & 24.52 & 291 & 72.48 & 0.02 & 0.2000 & 0.808 & 1.49 & 77.87 & 0.35 & 0.0187 & 0.297 & 26.13 \\
\hline CP/Wc/750/3 & 18.32 & 508 & 129.15 & 0.29 & 0.0169 & 0.319 & 40.00 & 138.07 & 0.18 & 0.0357 & 0.209 & 34.37 \\
\hline CP/Wc/750/6 & 15.32 & 647 & 165.04 & 1.42 & 0.0035 & 0.173 & 94.86 & 153.11 & 0.62 & 0.0106 & 0.194 & 71.35 \\
\hline CP/Wc/750/9 & 11.23 & 908 & 412.44 & 2.00 & 0.0025 & 0.136 & 272.08 & 231.57 & 0.99 & 0.0067 & 0.165 & 92.60 \\
\hline CP/Wc/850/3 & 13.98 & 611 & 258.23 & 2.24 & 0.0023 & 0.127 & 181.44 & 164.30 & 0.57 & 0.0115 & 0.196 & 50.70 \\
\hline CP/Wc/850/6 & 7.00 & 1162 & 563.14 & 3.63 & 0.0014 & 0.085 & 436.36 & 204.31 & 0.47 & 0.0140 & 0.152 & 108.53 \\
\hline
\end{tabular}

The parameters $Q_{0}$ and $b$ were found to be much larger after physical activation than after a simple pyrolysis. They were calculated from the sorption isotherms of both the pollutant models which are of type L i.e. similar to the type I for gaseous species. According to the values of the separation factor $R_{L}$, the adsorption processes were revealed to be favourable with $\mathrm{CO}_{2}$-activated carbon. The values found for the parameter $1 / n$, significantly lower than 1, are coherent with isotherms of type L (Figs. 4 and 5). Nevertheless for the adsorptions of methylene blue by simply pyrolysed char (see figure 5), the values of the parameters $1 / n$ and $R_{L}$ are relatively high when compared to the others in Table 2, indicating behaviour far from a normal Langmuir process. Raising either time or temperature allows extending the degree of activation, the BET surface area, in addition to the factors $Q_{0}$ and $k$. In the same time, the factor $1 / n$ decreases, thus testifying to a more marked Langmuir behaviour of the adsorbent-adsorbate system, well depicted by the concave-shape of sorption isotherms (Figs. 4 and 5).

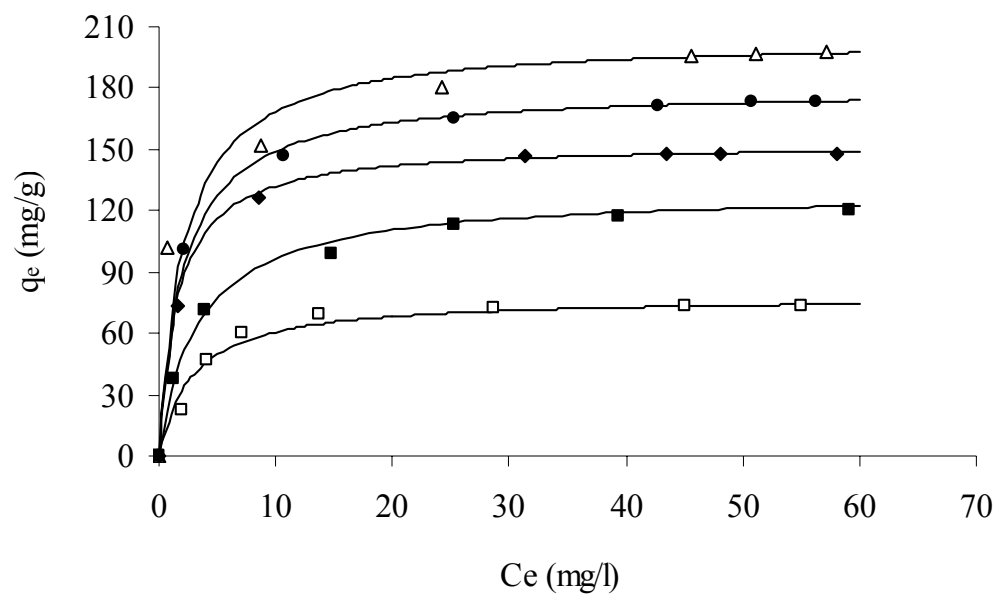

Fig. 4: Langmuir isotherms for phenol adsorption. Pyrolysed char $(\square) \mathrm{NP} / \mathrm{Wc} / 600 / 1, \mathrm{CO}_{2}$-activated

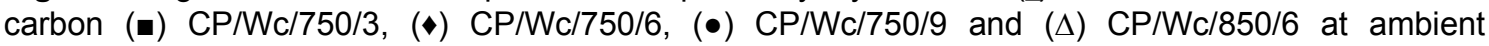
temperature. 


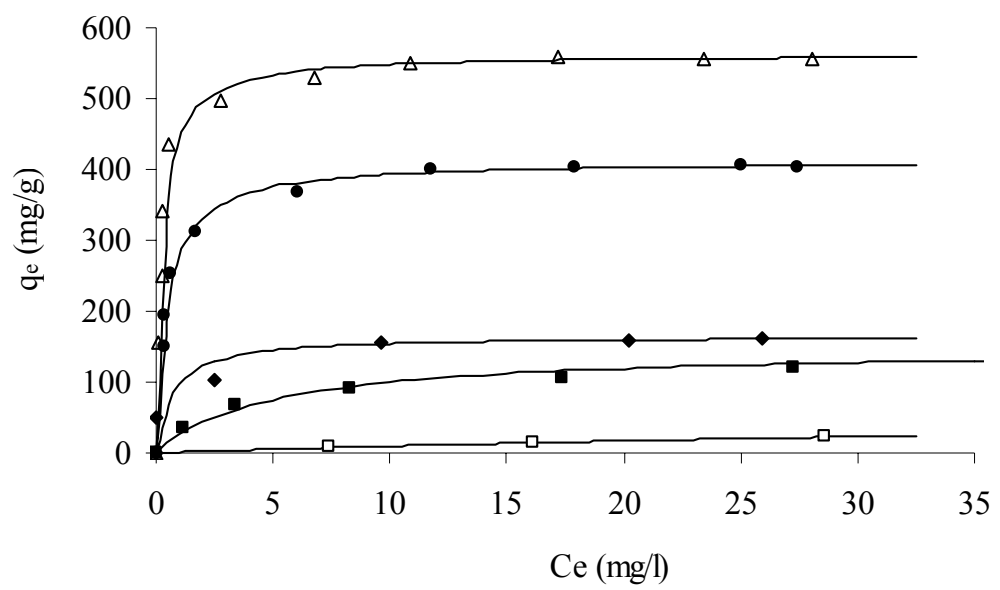

Fig. 5: Langmuir isotherms for adsorption of methylene blue Pyrolysed carbon ( $\square$ NP/ Wc /600/1,

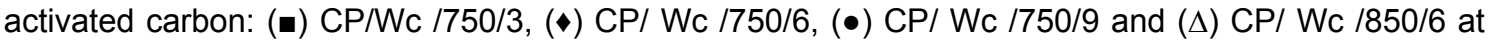
ambient temperature

BET surfaces areas and adsorption capacities for model pollutants rise with both the temperature and time of activation. Thus, when the activation time in plateau passed from 6 to 9 hours, the increase in surface area was $300 \mathrm{~m}^{2} \mathrm{~g}^{-1}$ for A.C. from thermo-compressed wood, whereas it was only $25 \mathrm{~m}^{2} \mathrm{~g}^{-1}$ for A.C. from virgin wood. Unfortunately, a drastic decrease in the mass yield in A.C. occurs with increasing time and temperature of activation. The mass yield even drops to only 7-8 \% for A.C. with usual BET surface areas larger than $1000 \mathrm{~m}^{2} \mathrm{~g}^{-1}$. From Table 2 it is clear that the adsorption capacity of methylene blue varied as the BET surface area. In the case of phenol, this trend was not observed. It can be assumed that phenol adsorption does not only depend on the BET surface area, but also on the microporous nature of adsorbent, which is not the case with a larger molecule such as methylene blue. With other investigators, Lopez-Gonzalez et al. (1980) have observed, as in the present work, that slightly activated carbon or simply carbonised chars exhibit a quasi null adsorption capacity of methylene blue. Indeed, this kind of adsorbent shows a very low BET surface area, although its structure is exclusively micro-porous.

It is obvious from Table 1 that the pre-treatment of thermo-compression has an enhancing effect upon the mass yield in A.C. Concerning the adsorption capacity, a slight enhancing effect is observed only in the case of phenol adsorption.

\section{Chemical Activation}

As shown by Fig. 6, the adsorption isotherms of $\mathrm{N}_{2}$ at $77 \mathrm{~K}$ for $\mathrm{KOH}$-activated carbon are clearly of type I. Not exhibiting any hysteresis, such isotherms are typical of a structure mainly microporous with a narrow distribution of pore sizes. By contrast, $\mathrm{H}_{3} \mathrm{PO}_{4}$-activated carbon as Acticarbone CXV showed a sorption isotherm of $\mathrm{N}_{2}$ very different, practically of type IV, which is indicative of a solid material rich in mesopores. The hysteresis of H4 type indicates a shape of pores more flat than cylindrical. Issa and Teresa (2000) have reported some similar influences of the activating agent, alkaline and acidic, on the aspect of sorption isotherms. Table 2 also regroups the main properties of $\mathrm{KOH}$-activated char from various precursors: virgin and compressed wood, coconut shell and olive stones. By comparing the data in Tables 1 and 2, it can be concluded that the mass yields are significantly higher for the $\mathrm{KOH}$-activated carbon than for the $\mathrm{CO}_{2}$-activated samples, with the same BET surface area. 
Furthermore, the $\mathrm{KOH}$ activation generates microporosity higher than any other mode of activation. It can be noted that the average pores diameter for $\mathrm{KOH}$-activated carbons was found to be below $2 \mathrm{~nm}$, indicating a rather microporous structure. The commercial activated carbon Acticarbone CXV, with an average pores diameter of $3.3 \mathrm{~nm}$ and a high mesopores surface area, can therefore be classified as mesoporous material. Issa and Teresa (2000) have shown that the $\mathrm{KOH}$ activated carbons have a homogeneous microporosity and a high surface area, while those activated by phosphoric acid exhibit a rather high mesoporous volume and a significantly lower surface area.

After activation, the washing of A.C. up to a neutral $\mathrm{pH}$ was crucial to remove the incrustations of mineral matter within the pores. Hence, in the present study, the measure of the BET surface area of a $\mathrm{KOH}$ activated carbon was $634 \mathrm{~m}^{2} \mathrm{~g}^{-1}$ before washing, and 1792 $\mathrm{m}^{2} \mathrm{~g}^{-1}$ after washing.

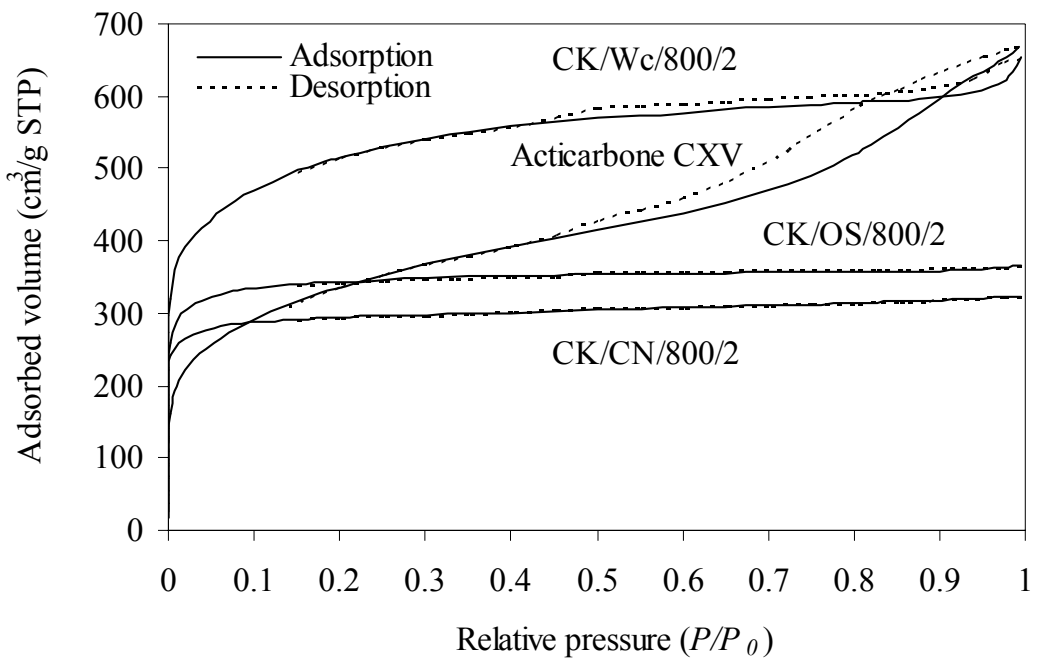

Fig. 6: $\mathrm{KOH}$ activated carbon. Adsorption-desorption isotherms of $\mathrm{N}_{2}$ at $77 \mathrm{~K}$

All tests of chemical activation were carried out with a plateau duration fixed to 2 hours. The variable parameters were the initial $\mathrm{KOH}$ content, the temperature of plateau, and the precursor material. First of all, it should be noted that an increase in the $\mathrm{KOH}$ content improved all the properties of activated carbon, except the mass yield as shown in Table 3 . However, a KOH content of 0.125 appears too low, since the corresponding BET surface area was only $428 \mathrm{~m}^{2} \mathrm{~g}^{-1}$. In the same experimental conditions, the BET surface area amounted to $1589 \mathrm{~m}^{2} \mathrm{~g}^{-1}$, with a $\mathrm{KOH}$ content equal to 1 . To achieve a satisfactory value of the BET surface area, the $\mathrm{KOH}$ content must not be lower than 0.4. For comparison, at $780{ }^{\circ} \mathrm{C}$ and one hour activation time, Wu et al (2005) reported surface area of 891 and $1371 \mathrm{~m}^{2} \mathrm{~g}^{-1}$ with $\mathrm{KOH}$ content of 0.5 and 1 respectively. These surface areas are close to those found in the present work (see Table 3). As other investigators, Wu et al. (2005) tested a larger $\mathrm{KOH}$ content up to 6 leading to activated carbon with a very high surface area up to $2794 \mathrm{~m}^{2} \mathrm{~g}^{-1}$. However, large $\mathrm{KOH}$ content results in too expensive activated carbons as far as a very high surface area is not really needed for usual applications.

All the properties of A.C. increase with the temperature of the plateau. A temperature of $600{ }^{\circ} \mathrm{C}$ is however too low to confer to the produced A.C. a high specific surface area of pores i.e. over $1000 \mathrm{~m}^{2} \cdot \mathrm{g}^{-1}$. Concerning the precursor material, the A.C. from wood exhibits a better BET surface area than the A.C. from the other precursors. An acid-activated carbon as 
Acticarbon CXV has a rather poor adsorption capacity in phenol and methylene blue despite of a good BET surface area $\left(1210 \mathrm{~m}^{2} \cdot \mathrm{g}^{-1}\right)$, therefore, it should be less suited to water purification than a $\mathrm{KOH}$ activated carbon.

For the tested solutions of phenol, the initial $\mathrm{pH}$ was in the range 7-7.8. As reported by Rengaraj et al. (2002), the phenol removal is the highest and is constant in the $\mathrm{pH}$ range $4-9$, while out of this range, the removal efficiency decreases. In the case of methylene blue adsorption, the $\mathrm{pH}$ was not fixed by addition of buffer solution, thus the $\mathrm{pH}$ was ranging from 7 (concentration $30 \mathrm{mg} / \mathrm{l}$ ) to 8.4 (concentration $200 \mathrm{mg} / \mathrm{l}$ ). It was demonstrated by various investigators such as El Qada et al. (2006) that the $\mathrm{pH}$ does not affect the uptake efficiency of methylene blue within a $\mathrm{pH}$ ranging from 4 to 9 , while at alkaline $\mathrm{pH}(\geq 11)$ the uptake is higher.

The experimental isotherms for phenol and methylene blue were well fitted by the Langmuir model, as illustrated by Figs. 7 and 8. The parameter $Q_{0}$ related to both the model pollutants varied as the BET surface area when using $\mathrm{KOH}$ as activating agent, while the dependence of the parameter $b$ with the BET surface was not so clear. From Table 3 it can also be noted that the very low values of the separation factor, $R_{L}$, attest to the favourable sorption power of all the $\mathrm{KOH}$-activated carbons from the various precursors, moreover, as for the $\mathrm{CO}_{2}$ activated chars, there is a good concordance between the parameters $Q_{0}$ and $k$. In all cases, the values of the parameter $1 / n<<1$, are indicative of a Langmuir process and of very weak interactions between molecules of solute. However, the influence of the experimental conditions upon the parameter $1 / n$ is not obvious. There was a visible effect of the $\mathrm{KOH}$ content; indeed, $1 / n$ was clearly higher when the $\mathrm{KOH}$ content was below $50 \%$. Besides, the parameter $1 / n$ decreased with increasing temperatures, which could be justified by an evolution of the sorption system towards a normal Langmuir process.

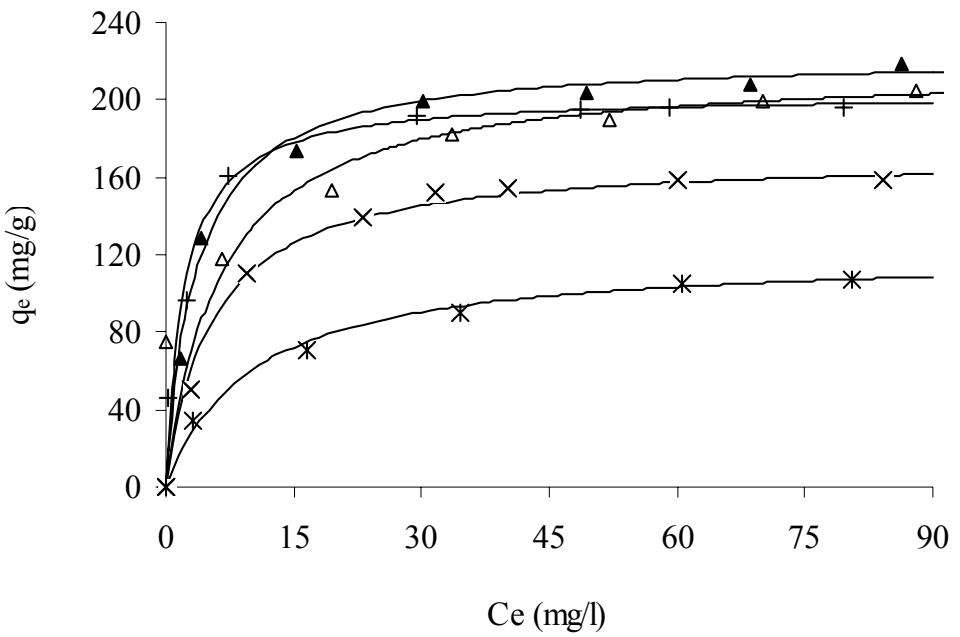

Fig. 7: Langmuir isotherms at $25{ }^{\circ} \mathrm{C}$ for the phenol adsorption: $(\Delta) \mathrm{CK} / \mathrm{Wc} / 800 / 2,(\Delta)$ CK/W/800/2, (x) CK/OS/800/2, (+) CK/CN/800/2, (*) Acticarbone CXV 
Table 2: Main Characteristics of $\mathrm{KOH}$ Activated Carbons.

\begin{tabular}{|c|c|c|c|c|c|c|c|c|c|c|c|c|c|}
\hline \multirow{3}{*}{$\begin{array}{l}\text { Activating } \\
\text { Agent }\end{array}$} & \multirow{3}{*}{$\begin{array}{l}\text { Activated } \\
\text { Carbon }\end{array}$} & \multirow{3}{*}{$\begin{array}{c}\text { Mass } \\
\text { Yield (\%) }\end{array}$} & \multirow{3}{*}{$\begin{array}{c}\text { Surface } \\
\text { area } \\
\left(\mathrm{m}^{2} \cdot \mathrm{g}^{-1}\right)\end{array}$} & \multicolumn{5}{|c|}{ Methylene blue } & \multicolumn{5}{|c|}{ Phenol } \\
\hline & & & & \multicolumn{3}{|c|}{ Langmuir } & \multicolumn{2}{|c|}{ Freundlich } & \multicolumn{2}{|c|}{ Langmuir } & \multicolumn{3}{|c|}{ Freundlich } \\
\hline & & & & $\begin{array}{c}Q_{0} \\
\left(\mathrm{mg} \cdot \mathrm{g}^{-1}\right)\end{array}$ & $\begin{array}{l}b \\
\left(1 . \mathrm{mg}^{-1}\right)\end{array}$ & $R_{L}$ & $1 / n$ & $k$ & $\begin{array}{c}Q_{0} \\
\left(\mathrm{mg} \cdot \mathrm{g}^{-1}\right)\end{array}$ & $\begin{array}{c}b \\
\left(\mathrm{l} . \mathrm{mg}^{-1}\right)\end{array}$ & $R_{L}$ & $1 / n$ & $k$ \\
\hline \multirow{8}{*}{$\mathrm{KOH}$} & CK/W/600/2 & 21.56 & 766 & 140.5 & 0.88 & 0.0056 & 0.083 & 96.68 & 131.4 & 0.12 & 0.0526 & 0.334 & 30.17 \\
\hline & $\mathrm{CK} / \mathrm{Wc} / 600 / 2$ & 24.09 & 906 & 169.4 & 0.64 & 0.0077 & 0.086 & 116.42 & 147.9 & 0.14 & 0.0454 & 0.293 & 40.84 \\
\hline & CK/W/700/2 & 18.12 & 1358 & 621.6 & 4.66 & 0.0011 & 0.124 & 421.42 & 164.3 & 0.22 & 0.0294 & 0.260 & 56.46 \\
\hline & CK/Wc/700/2 & 20.61 & 1589 & 646.1 & 5.10 & 0.0010 & 0.167 & 401.99 & 320.4 & 0.30 & 0.0217 & 0.242 & 116.41 \\
\hline & CK/W/800/2 & 15.98 & 1773 & 673.4 & 2.86 & 0.0017 & 0.082 & 495.80 & 216.4 & 0.28 & 0.0233 & 0.215 & 80.63 \\
\hline & $\mathrm{CK} / \mathrm{Wc} / 800 / 2$ & 18.32 & 1792 & 631.2 & 3.58 & 0.0014 & 0.060 & 498.22 & 227.6 & 0.20 & 0.0323 & 0.212 & 87.77 \\
\hline & $\mathrm{CK} / \mathrm{CN} / 800 / 2$ & 25.37 & 986 & 235.6 & 4.86 & 0.0010 & 0.062 & 118.52 & 203.6 & 0.23 & 0.0282 & 0.251 & 75.37 \\
\hline & $\mathrm{CK} / \mathrm{OS} / 800 / 2$ & 24.12 & 1155 & 301.2 & 9.09 & 0.0005 & 0.025 & 284.44 & 171.4 & 0.42 & 0.0156 & 0.323 & 46.80 \\
\hline $\mathrm{H}_{3} \mathrm{PO}_{4}$ & Acticarbone CXV & - & 1210 & 235.6 & 8.31 & 0.0006 & 0.126 & 168.14 & 120.6 & 0.18 & 0.0357 & 0.361 & 23.86 \\
\hline
\end{tabular}

Table 3: The effect of $\mathrm{KOH}$ content on the different characteristics of the activated carbons.

\begin{tabular}{|c|c|c|c|c|c|c|c|c|c|c|c|c|}
\hline \multirow{3}{*}{$\begin{array}{l}\text { Activated } \\
\text { Carbon }\end{array}$} & \multirow{3}{*}{$\begin{array}{c}\text { Mass } \\
\text { Yield } \\
(\%)\end{array}$} & \multirow{3}{*}{$\begin{array}{l}\text { Surface area } \\
\qquad\left(\mathrm{m}^{2} \cdot \mathrm{g}^{-1}\right)\end{array}$} & \multicolumn{5}{|c|}{ Methylene blue } & \multicolumn{5}{|c|}{ Phenol } \\
\hline & & & \multicolumn{3}{|c|}{ Langmuir } & \multicolumn{2}{|c|}{ Freundlich } & \multicolumn{3}{|c|}{ Langmuir } & \multicolumn{2}{|c|}{ Freundlich } \\
\hline & & & $\begin{array}{l}Q_{0} \\
\left(\mathrm{mg} \cdot \mathrm{g}^{-1}\right)\end{array}$ & $\begin{array}{l}b \\
\left(1 . \mathrm{mg}^{-1}\right)\end{array}$ & $R_{L}$ & $1 / n$ & $k$ & $\begin{array}{c}Q_{0} \\
\left(m g \cdot g-{ }^{-1}\right)\end{array}$ & $\begin{array}{c}b \\
\left(1 . \mathrm{mg}^{-1}\right)\end{array}$ & $R_{L}$ & $1 / n$ & $k$ \\
\hline $\mathrm{CK}_{1} / \mathrm{Wc} / 700 / 2$ & 20.61 & 1589 & 646.1 & 5.10 & 0.0010 & 0.167 & 401.99 & 320.4 & 0.30 & 0.0217 & 0.242 & 116.41 \\
\hline $\mathrm{CK}_{0.5} / \mathrm{Wc} / 700 / 2$ & 22.04 & 1108 & 442.2 & 4.06 & 0.0012 & 0.345 & 240.38 & 198.9 & 0.15 & 0.0425 & 0.319 & 49.29 \\
\hline $\mathrm{CK}_{0.125} / \mathrm{Wc} / 700 / 2$ & 24.82 & 428 & 63.7 & 0.11 & 0.0435 & 0.286 & 16.91 & 111.8 & 0.12 & 0.0526 & 0.304 & 33.23 \\
\hline
\end{tabular}




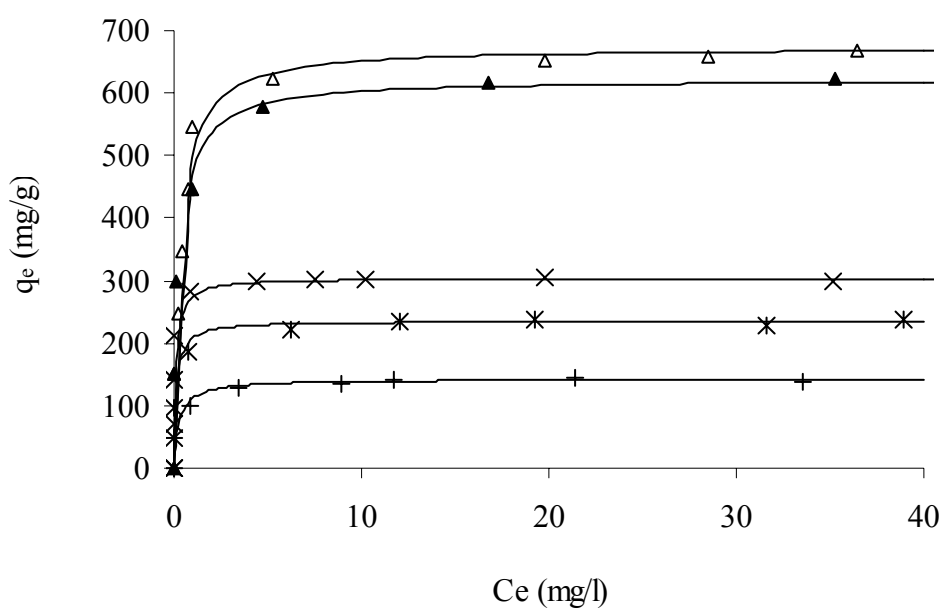

Fig. 8: Langmuir isotherms at $25{ }^{\circ} \mathrm{C}$ for the adsorption of methylene blue: $(\boldsymbol{\Delta})$ $\mathrm{CK} / \mathrm{Wc} / 800 / 2,(\Delta) \mathrm{CK} / \mathrm{W} / 800 / 2$, (x) CK/OS/800/2, (+) CK/CN/800/2, ( $\left.{ }^{*}\right)$ Acticarbone CXV

When considering the literature, there is a large scatter of the parameters of the Langmuir and Freundlich models due to a great diversity in the preparation mode of activated carbon and experimental conditions of adsorption (temperature, $\mathrm{pH}$, amount of A.C.). Nevertheless, the parameters obtained in the present work are in the same magnitude as those reported in literature (Kumar et al. 2007).

For instance, the extreme values of $\mathrm{Q}_{0}$ found from literature data, for phenol adsorption on A.C. were 3.22 and $572 \mathrm{mg} / \mathrm{g}$, while $\mathrm{Q}_{0}$ values of the present work were in the range $77-231 \mathrm{mg} / \mathrm{g}$ (see Table 2). As for $\mathrm{Q}_{0}$, all the other identified parameters of both the models $(\mathrm{b}, 1 / \mathrm{n}, \mathrm{k})$ were within the limit values given in literature for adsorption of phenol and methylene blue.

As indicated in Table 3, thermo-compression allows increasing the mass yield in A.C. from wood, by 2 to $3 \%$ that obviously appears economically interesting. Furthermore, thermo-compression results in some improvements, rather slight for the BET surface area and more important for the adsorption capacity of phenol. For the adsorption of methylene blue, thermo-compression does not show a marked enhancement as it has been observed by Abe et al. (2001) in adsorption tests with iodine solutions. These general trends are valid whatever the mode of activation.

The main characteristics of the different activated carbons determined by the $t$ plot method of Lippens and De Boer (1965) are presented in Table 4. The data of acticarbone CXV are in accordance with the trends revealed by the adsorption isotherms and confirms that it is mostly mesoporous in comparison to $\mathrm{KOH}$ activated carbon. The surface area of $\mathrm{KOH}$ activated carbon is strongly dependent on the ratio $\mathrm{KOH} / \mathrm{char}$. As testified by the average pore diameter $(>2.4 \mathrm{~nm})$, the $\mathrm{CO}_{2}$ activated carbon is also slightly mesoporous. Lastly, a thermo-compression seems improving the $\mathrm{KOH}$ activated carbon in terms of the BET surface area.

Khezami et. al. (2007). "Compressed wood activated carbon," BioResources 2(2), 193-209. 205 
Table 4: Adsorption of $\mathrm{N}_{2}$ at $77 \mathrm{~K}$

\begin{tabular}{|c|c|c|c|c|}
\hline$\underline{\text { Active carbon }}$ & $\frac{\text { Micropore }}{\frac{\text { surface area }}{\left(\mathrm{m}^{2} \cdot \mathrm{g}^{-1}\right)}}$ & $\begin{array}{c}\text { Mesopore } \\
\text { surface area } \\
\left(\mathrm{m}^{2} \cdot \mathrm{g}^{-1}\right)\end{array}$ & $\begin{array}{c}\text { Micropore } \\
\text { volume } \\
\left(\mathrm{cm}^{-3} . \mathrm{g}\right) \\
\end{array}$ & $\begin{array}{c}\text { Average pore } \\
\text { diameter } \\
(\mathrm{nm})\end{array}$ \\
\hline $\mathrm{CP} / \mathrm{W} / 850 / 6$ & 836 & 421 & 0.390 & 2.48 \\
\hline $\mathrm{CP} / \mathrm{Wc} / 850 / 6$ & 754 & 408 & 0.349 & 2.45 \\
\hline CK/W/600/2 & 545 & 221 & 0.250 & 1.88 \\
\hline $\mathrm{CK} / \mathrm{Wc} / 600 / 2$ & 715 & 191 & 0.331 & 1.99 \\
\hline $\mathrm{CK} / \mathrm{W} / 700 / 2$ & 978 & 380 & 0.449 & 1.96 \\
\hline $\mathrm{CK} / \mathrm{Wc} / 700 / 2$ & 1219 & 370 & 0.564 & 1.95 \\
\hline $\mathrm{CK} 0.5 / \mathrm{Wc} / 700 / 2$ & 849 & 192 & 0.425 & 1.91 \\
\hline $\mathrm{CK} 0.125 / \mathrm{Wc} / 700 / 2$ & 428 & 53 & 0.199 & 1.9 \\
\hline $\mathrm{CK} / \mathrm{W} / 800 / 2$ & 1492 & 282 & 0.468 & 2.14 \\
\hline $\mathrm{CK} / \mathrm{Wc} / 800 / 2$ & 1606 & 186 & 0.510 & 2.04 \\
\hline $\mathrm{CK} / \mathrm{CN} / 800 / 2$ & 836 & 150 & 0.388 & 2.02 \\
\hline $\mathrm{CK} / \mathrm{OS} / 800 / 2$ & 949 & 206 & 0.442 & 1.94 \\
\hline ActicarboneCXV & 230 & 980 & 0.091 & 3.33 \\
\hline
\end{tabular}

\section{CONCLUSIONS}

1. In this work it has been shown that preliminary thermo-compression is an easy way of conferring to a tender wood a bulk density about 2.5 times larger than its initial density.

2. A simple pyrolysis under neutral atmosphere reveals that mass yield in charcoal increases with the extent of thermo-compression. Thermo-compression also slightly increases the mass yield in activated carbon, regardless of the mode of activation.

3. Potassium hydroxide is an efficient activating agent, since it confers to an active carbon prepared from various biomasses a high microporosity but it presents the disadvantage of using high ratios KOH/A.C. resulting in an expensive activated carbon.

4. In addition to the mass yield in active carbon, mentioned above, the main benefit of thermocompression seems to lie in a better performance of phenol removal from aqueous solutions. In fact, the micro-porous structure partly generated by thermo-compression seems to enhance the adsorption of a small size molecule as phenol. 


\section{References Cited}

Abe I. , Fukuhara T., Iwasaki S., Yasuda K., Nagakawa K., Iwata Y., Kominami H., and Kera Y. (2001). "Development of a high density carbonaceous adsorbent from compressed wood," Carbon 39, 1485-1490.

Ahmadpour, A., and Do, D. D. (1996). "The preparation of active carbons from coal by chemical and physical activation," Carbon 34, 471-479.

Babel K. (2003).'Porous structure evolution of cellulose carbon fibres during heating in the initial activation stage," Fuel Processing Technology 85, 75-89.

Benefield L. D., Judkins J. F., and We, B. L.(1982). Process Chemistry for Water and Wastewater Treatment, Prentice-hall, Englewood Cliffs, NJ.

Brunauer S., Emett P.H. and Teller E. (1938). "Absorption of gases in multimolecular layers, “ J. A. Chem. SOC. 60, 309

Byrne C. E. and Nagle D. C. (1997a)."Carbonization of wood for advanced materials applications," Carbon 35, 259-266.

Byrne C.E., Nagle D.C. (1997b). "Carbonized wood monoliths-characterization," Carbon 35, 267-273.

Ehrburger, P., Addoun, A., Abdoun, F., and Donnet, J. B.(1986). "Carbonisation of coals in the presence of alkaline hydroxide and carbonates: formation of activated carbons," Fuel 65, 1447-1449.

El Qada, E. N., Allen, S. J., and Walker, G. M. (2006). “Adsorption of methylene blue onto activated carbon produced from steam activated bituminous coal: A study of equilibrium adsorption isotherm," Chemical Engineering J. 124, 103-110.

Franke F. H., and Meraikib, M. (1970). "Catalytic influence of alkalis on carbon gasification reaction," Carbon 8, 423-433.

Gergova, K., Petrov, N., and Eser, S. (1994). "Adsorption properties and microstructure of activated carbon produced from agricultural by-products by steam pyrolysis," Carbon 32; 693-702.

Guo, J., and Lua, A. C. (1998). "Characterisation of chars pyrolysed from oil palm stones for the preparation of activated carbons," J. Analytical and Applied Pyrolysis," 46, 113-125.

Guo J., and Lua, A. C. (1999). "Textural and chemical characteristics of activated carbon prepared from oil-palm stone with $\mathrm{H}_{2} \mathrm{SO}_{4}$ and $\mathrm{KOH}$ impregnation," Microporous and Mesoporous Materials 32, 111-117.

Hu, Z., and Srinivasan, M. P. (1999). "Preparation of high surface area activated carbons from coconut shell," Microporous and Mesoporous Materials 27, 11-18.

Hüttinger, K., J and Minges, R. (1986). "Influence of the catalyst precursor anion in catalysis of water vapour gasification of carbon by potassium," Fuel 65, 1112-1121.

Issa, I., and Teresa, J. (2000). "Comparison of the surface feature of two wood-based activated carbons," Ind. Eng. Chem. Res. 29, 301-306.

Khezami, L., and Capart, K. (2005). "Removal of chromium (VI) from aqueous solution by activated carbons: Kinetic and equilibrium studies," J. Hazardous Materials B123, 223-231.

Khezami et. al. (2007). “Compressed wood activated carbon," BioResources 2(2), 193-209. 207 
Khezami L., Chetouani A., Taouk B. and Capart R. (2005).'Production and characterisation of activated carbon from wood components in powder: cellulose, lignin, xylan," Powder Technology 157, 48-56

Kumar A., Kumar S., Kumar S., and Gupta, D. V. (2007). "Adsorption of phenol and 4nitrophenol on granular activated carbon in basal salt medium: Equilibrium and kinetics, “ J. Hazardous Material, in press.

Laine, J., and Yunes, S. (1992). "Effect of the preparation method on the pore size distribution of activated carbon from coconut shell," Carbon 30, 601-604.

Laine, J., Calafat, A., and Labady, M. (1989). "Preparation and characterisation of activated carbons from coconut shell impregnated with phosphoric acid," Carbon 27, 191-195.

Langmuir I. (1918). "The adsorption of gases on plane surfaces of glass, mica, platinum," J. Am. Chem. Soc. 40, 1361-1403.

Lippens, B. C., and De Boer, J. H. (1965). "Pore systems in catalysts. V. The t-method," J. Catalysis 4, 319-323.

Lopez-Gonzalez, J. D., Martinez-Vilchez, F., and Rodriguez-Reinoso, F. (1980). "Preparation and characterisation of active carbons from olive stones," Carbon 18, 413-418.

Marsh H. (1987). "Adsorption methods to study microporosity in coal and carbons - a critique," Carbon 25, 49-58.

Marsh, H., Yan, D. S., O'Grady, T. M., and Wennerberg, A. (1984). "Formation of active carbons from cokes using potassium hydroxide," Carbon 22, 603-611.

Mckay, G., Blair, H. S., and Gardner, J. R. (1982). "Adsorption of dye on chitin I. Equilibrium studies," J. Appl. Polym. Sci. 27, 3043.

O'Grady, T. M., and Wennerberg, A. N.(1986). "High surface area active carbon: Petroleum-derived carbons," ACS Symp. Ser., Washington DC, 303-302.

Pastor-Villegas J., Durán-Valle J., Valenzuela-Calahorro C. and Gómez-Serrano V. (1998).'Organic chemical structure and structural shrinkage of chars prepared from Rockrose," Carbon 36, 1251-1256.

Rengaray, Y., Seung-Hyeon, M. , Sivabalan, R., Arabindoo, B., and Murugesan, V. (2002). "Agricultural solid waste for the removal of organics: Adsorption of phenol from water and wastewater by palm seed coat activated carbon," Waste Management 22, $543-548$.

Rodriguez-Reinoso F. and Molina-Sabio M.(1994). "Activated carbons from lignocellulosic materials by chemical and/or physical activation," Carbon 30, 11111118.

Rouquerol, F., Rouquerol, J., and Sing, K. (1999). Adsorption by Powder and Porous Solids: Principles, Methodology and Applications, Academic Press, London.

Sodya Sai, P. M., Ahmed, J., and Kirshnaiak, K. (1997). "Production of activated carbon from coconut shell char in a fluidised bed reactor," Ind. Eng. Chem. Res. 36, 36253630 .

Toles, B. C., Rimmer, S., and Hower, J. C. (1996). "Production of activated carbons from Washington lignite using phosphoric acid activation," Carbon 34, 1419-1426.

Khezami et. al. (2007). "Compressed wood activated carbon," BioResources 2(2), 193-209. 208 
Tsai, W. T., Chang, C. Y., Lin, M. C., Chien, S. F., Sun, H. F., and Hsieh, M. F. (2001). "Adsorption of acid dye onto activated carbons prepared from agricultural waste bagasse by $\mathrm{ZnCl}_{2}$ activation," Chemosphere 45, 51-58.

Ubago-Pérez R., Carrasco-Marín F., Fairén-Jiménez D. and Moreno-Castilla C. (2006) "Granular and monolithic activated carbons from $\mathrm{KOH}$-activation of olive stones, " Microporous and Mesoporous Materials 92, 64-70.

Walker JR P.L. (1996). "Production of activated carbons: use of $\mathrm{CO}_{2}$ versus $\mathrm{H} 20$ as activating agent," Carbon 34, 1297-1299.

Warhurst A. M., Fowler, G. D., McConnachie, G. L., and Pollard, S. J. (1997). "Pore structure and adsorption characteristics of steam pyrolysis carbons from Moringa Oleifera," Carbon 35, 1039-1045.

Wu, F. C., Tseng, R. L., and Juang, R. S. (2005).“Preparation of highly micoporous carbons from wood by $\mathrm{KOH}$ activation for adsorption of dyes and phenols from water," Separation and Purification Technology 47, 10-19.

Article submitted: March 2, 2007; Article resubmitted with formatting changes: March 5, 2007; First round of reviewing completed: April 1, 2007; Revised article received: April 13, 2007; Revised article accepted: April 13, 2007; Published: April 15, 2007

Khezami et. al. (2007). "Compressed wood activated carbon," BioResources 2(2), 193-209. 209 